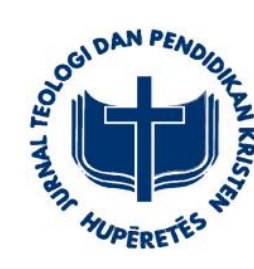

\title{
Pengajaran tentang Roh Kudus bagi Pembinaan Warga Jemaat Dewasa di Gereja Berdasarkan Surat Efesus
}

\author{
Deiby Ketlin Najoan \\ Sekolah Tinggi Teologi Kalimantan - Pontianak \\ Korepondensi: deiby.ketlin@gmail.com
}

\begin{abstract}
Abstrak: Pengajaran mengenai Roh Kudus merupakan tema penting dalam kurikulum pengajaran bagi pembinaan warga jemaat dewasa di gereja. Surat Paulus kepada jemaat di Efesus menekankan pentingnya hidup dalam pimpinan Roh Kudus. Gereja harus melaksanakan pengajaran mengenai Roh Kudus dalam pembinaan warga jemaat, supaya jemaat memiliki pemahaman yang benar. Melalui pendekatan studi literatur terkait dengan kajian surat Efesus, ditemukan bahwa pengajaran Roh Kudus dalam surat Efesus ialah Roh Kudus sebagai meterai, orang percaya dimeteraikan dengan Roh Kudus sewaktu percaya yang menandakan bahwa orang percaya adalah milik Allah. Roh Kudus menjadi jaminan bahwa orang percaya akan menerima apa yang telah dijanjikan-Nya. Orang percaya adalah tempat kediaman Roh Kudus, karena Roh Kudus yang mendiami orang percaya. Roh Kudus memberi kekuatan kepada orang percaya oleh Roh-Nya di dalam batin. Orang percaya tidak boleh mendukakan Roh Kudus, melainkan orang percaya diperintahkan untuk terus menerus dipenuhi oleh Roh Kudus. Roh Kuduslah yang menuntun orang percaya dalam berdoa. Kajian Alkitab dalam surat Efesus mengenai Roh Kudus dapat menjadi acuan bagi gereja untuk pelaksanaan kurikulum pengajaran tentang Roh Kudus bagi pembinaan warga jemaat dewasa. Ajaran alkitab dalam surat Efesus menjadi landasan tentang pentingnya pengajaran Roh Kudus bagi jemaat dewasa di gereja.
\end{abstract}

Kata kunci: Roh Kudus, orang dewasa, jemaat, pembinaan, gereja

Abstract: Teaching about the Holy Spirit is an important theme in the teaching curriculum for the formation of adult members of the church. Paul's letter to the Ephesians emphasized the importance of living under the leading of the Holy Spirit. The church must carry out the teaching of the Holy Spirit in the formation of the members of the congregation, so that the congregation has a correct understanding. Through a literature study approach related to the study of the Ephesians, it was found that the teaching of the Holy Spirit in Ephesians is the Holy Spirit as a seal, believers are sealed with the Holy Spirit when they believe which signifies that believers belong to God. The Holy Spirit is the guarantee that believers will receive what He has promised. Believers are the abode of the Holy Spirit, because the Holy Spirit indwells believers. The Holy Spirit empowers believers by His Spirit within. Believers should not grieve the Holy Spirit, but believers are commanded to be continually filled with the Holy Spirit. It is the Holy Spirit who guides believers in prayer. The Bible study in Ephesians about the Holy Spirit can be a reference for the church to implement a curriculum for teaching about the Holy Spirit for the formation of adult members of the congregation. The teachings of the Bible in the letter of Ephesians are the basis for the importance of teaching the Holy Spirit to adult members of the church.

Keywords: Holy Spirit, adults, congregation, formation, chruch 


\section{PENDAHULUAN}

Pendidikan orang dewasa dalam jemaat adalah bagian yang penting dan harus menjadi penekanan dalam melaksanakan pelayanan di gereja. Andar Ismail seperti yang dikemukakan oleh Sidjabat, menemukan enam alasan mengapa pendidikan bagi orang dewasa itu penting, dengan uraian sebagai berikut: pertama, Alkitab menyatakan perlunya pendidikan bagi orang dewasa. Kedua, makna tradisi para rasul dan posisi serta peran kaum awam di gereja dalam rencana Allah. Ketiga, orang dewasa mempunyai posisi strategis di masyarakat yang sarat dengan tantangan, oleh karena itu mereka memerlukan topangan. Keempat, peran orang dewasa sebagai orangtua dan pendidik iman serta moral anaknya. Kelima, orang dewasa memerlukan pertumbuhan spiritual dan moral. Keenam, para usia lanjut juga membutuhkan pembinaan gereja. ${ }^{1}$ Eli Tanya menyebutkan beberapa alasan mengapa diperlukan pendidikan warga jemaat untuk orang dewasa, antara lain: pertama, umat Kristen awam memiliki pengetahuan yang minimal sekali tentang Alkitab. Kedua, ajaran Alkitab sendiri yang berisikan pengajaran untuk semua sepanjang umur hidupnya. Ketiga, perkembangan zaman modern dan perubahan sosial yang cepat menuntut pemikiran serius dari orang dewasa. ${ }^{2}$

Bagi Ruth F. Selan, pembinaan warga jemaat bukan saja merupakan suatu proses belajarmengajar, melainkan suatu proses untuk mencapai perubahan hidup. Perubahan sebagai hasil dari proses pembinaan atau pendidikan yang terdiri dari: perubahan pengetahuan (kognitif), perubahan sikap (afektif), dan perubahan perbuatan yang dapat digambarkan sebagai kedewasaan dalam Kristus. Pada akhirnya untuk menyempurnakan setiap anak Tuhan dalam watak dan sikap sampai menjadi serupa dengan Kristus. ${ }^{3}$ Mencermati pernyataan yang dikemukakan oleh Selan bahwa pembinaan

${ }^{1}$ B. S. Sidjabat, Mendidik Warga Gereja Melalui Seri Selamat (Jakarta: BPK Gunung Mulia, 2018), 65-66.

${ }^{2}$ Eli Tanya, Gereja dan Pendidikan Agama Kristen (Sekolah Tinggi Teologi Cipanas, 1999), 129.

${ }^{3}$ Ruth F. Selan, Pedoman Pembinaan Warga Jemaat (Bandung: Kalam Hidup, 2000), 14. warga jemaat supaya mengalami perubahan, hal itu hanya dapat dikerjakan oleh Roh Kudus. Seperti yang ditegaskan oleh Sidjabat bahwa cara kerja Roh Kudus dalam mengubahkan kepribadian sangatlah kreatif. Roh Kuduslah yang menumbuhkan dan membangkitkan iman. ${ }^{4}$ Jadi, pengajaran tentang Roh Kudus bagi jemaat dewasa dilakukan supaya mereka memiliki pemahaman bahwa Roh Kudus sendiri yang dapat mengubah kepribadian mereka memiliki karakter seperti Kristus.

Pengajaran tentang Roh Kudus artinya bimbingan yang diberikan kepada warga jemaat untuk memahami ajaran Alkitab mengenai pribadi Allah Roh Kudus. Alasan yang dapat dikemukan mengenai pentingnya pengajaran Roh Kudus bagi jemaat di gereja, seperti yang dikemukakan oleh Sentot Sadono, mengutip John. F Arthur Jr., dengan mengatakan bahwa sebagai gereja masih sangat perlu mengkaji ulang pengenalan kita akan Roh Kudus, dengan tujuan supaya dengan pemahaman yang lengkap tentang Roh Kudus menurut Alkitab saja, kita benar-benar mampu dan siap mengevaluasi dan menentukan sikap yang bijaksana, hormat dan tegas terhadap doktrin, dan kegiatan-kegiatan yang diyakini sebagai gerakan Roh Kudus akhir zaman ini. ${ }^{5}$ Selanjutnya, Enns menegaskan bahwa Roh Kudus adalah salah satu pribadi dari Allah Tritunggal, oleh karena itu studi khusus tentang pribadi dan karya-Nya sama penting dengan studi yang lainnya. ${ }^{6}$ Selanjutnya, Billy Graham mengemukakan bahwa Roh Kudus adalah pribadi yang Ilahi: Ia adalah Allah. Ia kekal, Ia Mahakuasa, Ia Mahaada, Ia Mahatahu, Ia adalah Pencipta. ${ }^{7}$ Michael J. Anthony menguraikan bahwa meski Roh Kudus memiliki segala atribut Ilahi, Ia memiliki peran dan tujuan yang berbeda dari dua Pribadi lainnya dalam Trinitas. Dalam Injil Yohanes 14:26, Yesus memperkenalkan Roh Kudus kepada orang

${ }^{4}$ B. S. Sidjabat, Mengajar Secara Profesional (Bandung: Kalam Hidup, 2017), 76.

${ }^{5}$ Sentot Sadono, Doktrin Baptis Diantara Pandangan

Teologi Kristen (Semarang: STBI, 2011), 160.

${ }^{6}$ Paul Enns, The Moody Handbook of Theology (Malang: SAAT, 2008), 301.

${ }^{7}$ Billy Graham, Roh Kudus (Bandung: Lembaga Literatur Baptis, 2002), 17-19. 
percaya sebagai guru: ... tetapi penghibur, yaitu Roh Kudus, yang akan diutus oleh Bapa dalam nama-Ku, Dialah yang akan mengajarkan segala sesuatu kepadamu dan akan mengingatkan kamu akan semua yang telah Kukatakan kepadamu". Roh Kudus memiliki peran yang sangat penting dalam kehidupan pengikut Yesus pada masa kini dengan mengingatkan mereka prinsip-prinsip dan pengajaran Alkitab ketika menjalani kehidupan sehari-hari mereka. Dalam peran ini, Sang Penasehat Ilahi ini tidak hanya mengingatkan orang percaya mengenai apa yang harus mereka lakukan, tetapi juga mendorong mereka dengan bijaksana untuk melakukan apa yang benar. Bahkan oleh Roh Kudus seseorang dapat memahami apa yang telah Allah nyatakan melalui firman-Nya. Kehadiran Roh Kudus dalam diri seseorang akan memungkinkan orang tersebut untuk menikmati kehadiran Penasehat Ilahi yang mengajar, memberi dorongan, menenangkan, dan menegur. ${ }^{9}$ Dengan demikian bahwa setiap warga jemaat dewasa di gereja perlu memiliki pemahaman yang benar mengenai Roh Kudus. Oleh karena itu, pengajaran mengenai Roh Kudus harus menjadi salah satu tema penting dalam pembinaan warga jemaat dewasa di gereja.

Rasul Paulus sebagai gembala dan pendidik warga jemaat, dalam suratnya kepada jemaat di Efesus pada masa lampau, menekankan pentingnya mereka hidup dalam pimpinan Roh Kudus. Mereka patut mensyukuri hadirnya Roh Kudus sebagai anugerah keselamatan yang diterima oleh iman kepada Yesus Kristus (Ef. 1:13-14). Mereka patut menyadari sebagai tempat kediaman Roh Allah (Ef. 2:22). Jemaat dibimbing mengerti bahwa Roh Kudus mendiami hati mereka dan memberi kekuatan iman (Ef. 3:16). Roh Kudus tidak boleh dibuat berdukacita karena akar pahit, dosa dan kejahatan yang biasa dilakukan (Ef. 4:30). Roh Kudus patut memenuhi hidup mereka (Ef. 5:18). Jemaat dituntun untuk belajar menghadapi peperangan rohani dengan giat berdoa di dalam Roh (Ef. 6:11-13,18).

\footnotetext{
${ }^{8}$ Michael J. Anthony, Fondasi Pendidikan Abad 21 (Malang: Gandum Mas, 2017), 220.

${ }^{9}$ Ibid., 221.
}

Penelitian ini memberikan landasan biblika terkait dengan pengajaran tentang Roh Kudus bagi pembinaan warga jemaat dewasa di gereja berdasarkan surat Efesus. Pengajaran tentang Roh Kudus merupakan tema penting yang harus disampaikan atau dikhotbahkan, bahkan harus menjadi salah satu tema penting dalam kurikulum pengajaran di gereja dalam pembinaan warga jemaat. Ditinjau dari ajaran Alkitab dalam surat Efesus sebagai landasan tentang pentingnya pengajaran Roh Kudus bagi jemaat dewasa.

\section{METODE}

Metode yang digunakan dalam penelitian ini menggunakan metode atau pendekatan studi literatur, yang disebut juga sebagai metode studi pustaka. Di dalam metode ini, peneliti mengumpulkan sebanyak-banyaknya teori dan informasi dari bahan kepustakaan menyangkut topik penelitian. Bahan-bahan dari sumber pustaka tersebut pada umumnya terdiri dari konsep, pendapat, ide dan gagasan yang semuanya dipilih berdasarkan kesesuaian dan relevansinya terhadap topik penelitian. ${ }^{10}$ Karya ilmiah ini bersifat konseptual atau teoritis dan merupakan hasil penelitian kepustakaan dalam rangka memecahkan permasalahan yang ditemukan dan dikemukakan. Kepustakaan teologi yang dimaksud meliputi sumber-sumber pengetahuan dalam bidang-bidang Biblika, Sistematika, Historika, dan teologi Praktika. ${ }^{11}$

Adapun prosedur atau langkah-langkah dalam pendekatan studi literatur sebagai berikut: Pertama, pemilihan literatur yang relevan (jurnal, buku, majalah, web, ensiklopedia, dsb). Kedua, pembacaan literatur dan pembuatan catatan review terutama tinjauan kritis. Ketiga, pengelompokan dan sintesa ide atau gagasan sesuai sesuai pokok bahasan. Keempat, penulisan atau input konsep ke dalam paragraf. Salah satu peran utama dari studi literatur adalah memberi pasokan informasi mengenai kerangka teoritis

${ }^{10}$ Sonny Eli Zaluchu, "Metode Penelitian di dalam Manuskrip Jurnal Ilmiah Keagamaan” Jurnal Teologi Berita Hidup 3 No. 2 (2021): 249-266.

${ }^{11}$ B. S. Sidjabat, Pedoman Penulisan Tesis (Bandung: STAT, 2015), 2 \& 8. 
yang hendak dibangun peneliti sebagai landasan bagi pemecahan masalah. ${ }^{12}$ Studi literatur dalam penelitian ini terkait dengan kajian surat Efesus dengan pendekatan studi teologi bukan eksegesa.

\section{PEMBAHASAN}

\section{Kajian Pengajaran tentang Roh Kudus dalam Surat Efesus}

Salah satu pembahasan dalam surat Efesus adalah tentang Roh Kudus. Pembahasan tentang Roh Kudus sangat penting, seorang Kristen tidak akan pernah menjadi utuh atau dewasa, tanpa adanya pengetahuan meluas tentang Pribadi dan karya Roh Kudus. Roh Kudus adalah salah satu pribadi dari Allah Tritunggal. Roh Kudus, Pribadi ketiga Allah, menjalankan peran yang terus-menerus meski tidak terlihat dalam hubungan dan komunikasi antara manusia dan Allah. ${ }^{13}$ Roh Kudus mempunyai kedudukan yang sama dengan Allah Bapa, dan Allah Anak. ${ }^{14}$

Pengajaran Roh Kudus dalam surat Efesus terkait dalam beberapa hal, yaitu: 1) Roh Kudus sebagai meterai, 2) Roh Kudus sebagai jaminan, 3) Orang percaya sebagai tempat kediaman Roh Allah atau Roh Kudus, 4) Roh Kudus memberi kekuatan kepada orang percaya, 5) Jangan mendukakan Roh Kudus, 6) Pemenuhan oleh Roh Kudus, dan 7) Roh Kudus menuntun orang percaya dalam berdoa. Adapun tinjauan pengajaran tentang Roh Kudus dalam surat rasul Paulus kepada jemaat di Efesus, antara lain:

\section{Roh Kudus sebagai Meterai}

(Ef. 1:13)

Orang percaya "dimeteraikan" dengan Roh sewaktu percaya, artinya, kehadiran Roh dalam diri orang-orang yang percaya merupakan cap yang menandakan milik Allah. ${ }^{15}$ Kebenaran

${ }^{12}$ Zaluchu, "Metode Penelitian di dalam Manuskrip Jurnal Ilmiah Keagamaan,” 249-266.

${ }^{13}$ G. D. Fee, dkk., "Roh Kudus" dalam Kamus Gambaran Alkitab (Surabaya: Momentum, 2011), 17-21.

${ }^{14}$ Norman Geisler, "Siapakah Roh Kudus Itu?" dalam Pola Hidup Kristen (Malang: Gandum Mas, 2002), 224.

${ }^{15}$ Leon Morris, Teologi Perjanjian Baru (Malang: Gandum Mas, 2006), 106. penting muncul dari pemeteraian oleh Roh Kudus, menurut Paul Enns ialah:1) Meterai Roh Kudus atas orang percaya menunjukkan bahwa orang percaya adalah milik Allah. 2) Hal itu menunjukkan sekuritas, meterai itu bersifat permanen "menjelang hari penyelamatan" (Ef. 4:30). 3) Hal itu juga menunjukkan otoritas Allah atas orang percaya. ${ }^{16}$ Selanjutnya, Matthew Henry mengatakan bahwa kita dimeteraikan Roh Kudus, yang dijanjikan-Nya itu (ay. 13), Roh yang mulia itu adalah kudus, dan Ia membuat kita menjadi kudus. ... oleh-Nya orang-orang percaya dimeteraikan, artinya dipisahkan dan disisihkan bagi Allah, dikhususkan dan ditandai sebagai milik-Nya. ${ }^{17}$ Selanjutnya, Walvoord dan Zuck berpendapat bahwa:

God is the One who seals, Christ is the sphere in which the seal is done, and the Holy Spirit is the instrument of the seal. ... The Holy Spirit who seals is a deposit guaranteeing our inheritance. ${ }^{18}$

Dengan bermeteraikan Roh Kudus, maka orang yang bersangkutan adalah milik Allah, Roh Kudus menyatakan kepada kita kehendak Allah dan sekaligus memungkinkan kita untuk melaksanakan kehendak itu. ${ }^{19}$ Ralph P. Martin dalam tulisannya menjelaskan bahwa pemeteraian dihubungkan dengan RohKudus yang dijanjikan yang tinggal dalam orang yang telah percaya kepada-Nya. Kita dijadikan milik Allah pada saat kita percaya dan dimeteraikan. Tindakan-tindakan percaya dan pemeteraian oleh Roh Kudus terjadi serempak. ${ }^{20} \mathrm{Hal}$ itu juga ditegaskan oleh O'brien dengan mengatakan bahwa peristiwa percaya dan dimeteraikan adalah dua sisi pada satu peristiwa.

${ }^{16}$ Enns, The Moody Handbook of Theology, 314.

${ }^{17}$ Matthew Henry, Surat Galatia, Efesus, Filipi, Kolose, 1 E 2 Tesalonika, Timotius, Titus, Filemon (Surabaya: Momentum, 2015), 139.

${ }^{18}$ John F. Walvoord \& Roy B. Zuck, The Bible Knowledge Commentary (New York: Zondervan Bible Publisher, 1984), 619.

${ }^{19}$ William Barclay, Pemahaman Alkitab Setiap Hari: Galatia dan Efesus (Jakarta: BPK Gunung Mulia, 1999), 129.

${ }^{20}$ Ralp P. Martin, "Efesus" dalam Tafsiran Alkitab Masa Kini 3 (Jakarta: Yayasan Komunikasi Bina Kasih, 2007), 581 
Membicarakan Roh Kudus sebagai meterai, kita perlu melihatnya dalam konsep kepemilikan dan perlindungan." ${ }^{21}$ Rasul Paulus juga mengambarkan meterai oleh Roh Kudus dalam 2 Korintus 1:21-22 "Sebab Dia yang telah meneguhkan kami bersama-sama dengan kamu di dalam Kristus, adalah Allah yang telah mengurapi, memeteraikan tanda milik-Nya atas kita dan yang memberikan Roh Kudus di dalam hati kita sebagai jaminan dari semua yang telah disediakan untuk kita." Roh Kudus sebagai meterai dalam surat Efesus merupakan cap yang menandakan bahwa seseorang telah menjadi milik Allah ketika dia percaya kepada Tuhan Yesus Kristus.

Roh Kudus sebagai Jaminan

(Ef. 1:14)

Ayat ini menyatakan natur dari Roh Kudus sebagai uang muka bagi glorifikasi terakhir dan yang sempurna untuk kita di surga. Bagian ini juga menjelaskan bahwa Roh adalah uang muka Allah bagi masa depan orang beriman, suatu pemberian pendahuluan dan suatu cicipan dari warisan yang akan datang. ${ }^{22}$ William Barclay menjelaskan bahwa Roh Kudus disebut sebagai jaminan penebusan kita dapat digambarkan dengan sebagian dari harga beli suatu barang yang dibayarkan lebih dulu sebagai jaminan bahwa sisanya akan dilunaskan dalam waktu yang ditentukan. ${ }^{23}$ Selanjutnya, O'brien menjelaskan bahwa: Kata jaminan memiliki makna "uang muka" atau "janji", dan dalam PB digunakan hanya dalam tulisan-tulisan Paulus dan selalu dengan rujukan kepada Roh Kudus. Dalam Efesus 1:14, Roh Kudus diterima sebagai jaminan bagian kita: dengan memberikan Dia kepada kita, Allah tidak hanya menjanjikan kita bagian final kita tetapi sesungguhnya membuat kita bisa mencicipi lebih dahulu bagian tersebut, sekalipun hanyalah 'bagian kecil dari apa yang

\footnotetext{
${ }^{21}$ Peter T. O'brien, Surat Efesus (Surabaya: Momentum, 2013), 148-149.

${ }^{22}$ Fee, dkk., "Roh Kudus" dalam Kamus Gambaran Alkitab, 919.

${ }^{23}$ Barclay, Pemahaman Alkitab Setiap Hari: Galatia dan Efesus, 129.
}

akan kita dapatkan di masa depan." ${ }^{24}$ Roh Kudus sebagai jaminan adalah simbol dari keamanan dan kepastian orang percaya dalam Kristus. ${ }^{25}$

Matthew Henry mengatakan bahwa jaminan itu merupakan bagian dari pembayaran dan menjamin jumlah pembayaran sepenuhnya. ${ }^{26}$ Ralph P. Martin berpendapat bahwa orang Kristen menerima jaminan, 'cicilan pertama' (Yun. arrabon) dari Roh Kudus pada pertobatan, dan ia menantikan penyempurnaan terakhir dari rencana Allah itu. ${ }^{27}$ Yang dimaksud dengan jaminan dalam bagian ini adalah uang tanda jadi atau uang muka, yaitu bagian yang dibayarkan pertama kali sebagai jaminan bahwa kelak akan dibayar seluruhnya. Roh Kudus yang ada pada kita menjadi jaminan (tanda jadi) bahwa kita akan menerima apa yang telah dijanjikan. ${ }^{28}$ Dengan demikian dapat dikatakan bahwa Roh Kudus sebagai jaminan bagi orang percaya untuk memperoleh atau menerima warisan yang telah dijanjikan-Nya.

\section{Roh Kudus Mendiami Orang Percaya} (Ef. 2:22)

O'brien menjelaskan bagian ini dengan menegaskan bahwa keanggotaan bait suci ini berarti didiami oleh Roh Allah. Bait tersebut adalah umat-Nya yang di dalam mereka Ia tinggal dengan Roh-Nya. ${ }^{29}$ Matthew Henry dalam tulisannya mengatakan bahwa setiap orang percaya yang sejati adalah bait Allah yang hidup, menjadi tempat kediaman Allah, di dalam Roh. Sekarang Allah berdiam di dalam diri setiap orang percaya, karena mereka telah menjadi Bait Allah melalui pekerjaan Roh yang mulia. ${ }^{30}$ Selanjutnya, Walvoord dan Zuck mengatakan:

${ }^{24}$ O'brien, Surat Efesus, 150.

${ }^{25}$ Enns. The Moody Handbook of Theology, 313.

${ }^{26}$ Henry, Surat Galatia, Efesus, Filipi, Kolose, 1 E 2 Tesalonika, Timotius, Titus, Filemon, 139.

${ }^{27}$ Martin, "Efesus" dalam Tafsiran Alkitab Masa Kini 3, 581 .

${ }^{28}$ Robert G. Bratcher dan Eugene A. Nida, Pedoman Penafsiran Alkitab Surat Paulus Kepada Jemaat di Efesus (Jakarta: Lembaga Alkitab Indonesia, 2013), 24.

${ }^{29} \mathrm{O}$ 'brien, Surat Efesus, 272-273.

${ }^{30}$ Henry, Surat Galatia, Efesus, Filipi, Kolose, 1 E 2 Tesalonika, Timotius, Titus, Filemon, 161. 
"In this Age God dwells in His new temple which is constructed not from inanimate materials but of living believers. The Holy Spirit indwells each individual believer. The temple in Ephesians 2:21-22 refers to the Holy Spirit's corporate "dwelling" (cf. 1 Cor. 3:16; 2 Cor. 6:16), His "temple" composed of all Jewish and Gentile believers." 31

Tempat kediaman Allah dapat diterjemahkan menjadi tempat Allah berada atau rumah Allah, di dalam Roh atau melalui Roh. Roh merupakan cara atau bentuk Allah berada atau bekerja dalam rumah-Nya, yaitu dalam jemaat yang adalah tubuh Kristus. Orang percaya adalah rumah tempat Allah tinggal melalui Roh-Nya atau tempat Allah yang adalah Roh berada. ${ }^{32}$ Surat Efesus menegaskan bahwa orang percaya adalah tempat kediaman Roh Kudus. Roh Kudus berdiam dalam hidup orang percaya terjadi ketika seseorang percaya kepada-Nya. Orang yang sudah didiami oleh Roh Kudus, harus hidup dalam bimbingan Roh Kudus atau mengijinkan Roh Kudus bekerja dalam dirinya, mengikuti kehendak-Nya.

\section{Roh Kudus Memberi Kekuatan kepada Orang Percaya}

(Ef. 3:16)

Menguatkan 'hidup batiniah' orang percaya merupakan pekerjaan Roh Kudus. Berdiamnya Kristus dalam hati orang percaya adalah jaminan kekuatan itu. ${ }^{33}$ Bagian ini menunjukkan bahwa Allah yang memberikan kekuatan atau kemampuan kepada umat-Nya melalui RohNya. ${ }^{34}$ Paulus memanjatkan doa kiranya mereka dikuatkan oleh kuasa Roh dalam batin mereka, dan supaya makin lama makin mantap dan teguh oleh iman, sebagai dampak dari didiami

\footnotetext{
${ }^{31}$ Walvoord \& Zuck, The Bible Knowledge Commentary, 628.

${ }^{32}$ Bratcher dan Nida, Pedoman Penafsiran Alkitab Surat Paulus Kepada Jemaat di Efesus, 64-65.

${ }^{33}$ Martin. "Efesus" dalam Tafsiran Alkitab Masa Kini 3, 592 .

${ }^{34}$ Bratcher dan Nida, Pedoman Penafsiran Alkitab Surat Paulus Kepada Jemaat di Efesus, 84.
}

oleh Kristus dalam Roh Kudus. ${ }^{35}$ Barclay mengemukakan bahwa apabila kita berserah kepada Roh Kudus dan membiarkan Dia menguasai manusia batiniah, maka kita dapat berhasil dalam hidup memuliakan Allah. ${ }^{36}$ Selanjutnya, Matthew Henry dalam tulisannya mengatakan bahwa: Kekuatan dari Roh Allah dalam batin manusia adalah kekuatan yang terbaik dan yang paling diinginkan, kekuatan dalam jiwa, kekuatan dalam iman, dan kasih karunia lainnya. Kekuatan itu juga merupakan kekuatan untuk melayani Allah dan melaksanakan tugas kita, serta untuk bertekun dalam cara hidup kristiani dengan keteguhan dan sukacita. ${ }^{37}$ Dapat dikatakan bahwa ketergantungan total orang Kristen atas pemberian kuasa oleh Roh memperlihatkan betapa kehadiran Roh itu mutlak perlu bagi kehidupan Kristen dan betapa orang Kristen mustahil tidak memiliki Roh. ${ }^{38}$

Permohonan Paulus dalam Efesus 3:16-17 ini dijelaskan oleh Walvoord \& Zuck dengan mengatakan "the purpose of the request is that they may have power (exischysite, "have inherent strength"), together with all the saints, to grasp how wide and long and high and deep is the love of Christ." ${ }^{39}$ Melalui penguatan manusia batin oleh Roh Allah dan berdiamnya Kristus di dalam hati mereka, para pembaca dibangunkan dalam kasih sehingga mereka akan memahami kebesaran kasih Allah. ${ }^{40}$ Leon Morris dalam tulisannya menguraikan bahwa: Kasih sebagai ciri khas utama dari orang Kristen; adalah indah sekali jika kita bersama-sama dengan segala orang kudus dapat memahami, betapa lebar dan panjangnya dan tingginya dan dalamnya kasih Kristus, dan dapat mengenal kasih itu, sekalipun ia melampaui segala pengetahuan. Paulus memandang kasih sebagai ciri khas utama dari

\footnotetext{
${ }^{35}$ John Stott, Efesus (Jakarta: Yayasan Komunikasi Bina Kasih, 2013), 132.

${ }^{36}$ Barclay, Pemahaman Alkitab Setiap Hari: Galatia dan Efesus, 81.

${ }^{37}$ Henry, Surat Galatia, Efesus, Filipi, Kolose, 1 E 2 Tesalonika, Timotius, Titus, Filemon, 174.

${ }^{38}$ Donald Guthrie, Pengantar Perjanjian Baru Volume 2 (Surabaya: Momentum, 2001), 196.

${ }^{39}$ Walvoord \& Zuck, The Bible Knowledge Commentary, 631.

${ }^{40} \mathrm{O}$ 'brien, Surat Efesus, 319.
} 
orang Kristen. Di tengah umat manusia yang didorong oleh ambisi, keserakahan, kepalsuan, egoism, dan semacamnya, Paulus mengharapkan supaya orang-orang Kristen menonjol karena kasih mereka, baik kepada individu maupun sebagai komunitas. ${ }^{41}$

Selanjutnya, Boice mengatakan karena Roh Kristus ditanamkan dalam diri orang-orang Kristen, kita harus menunjukkan kasih yang besar, mengubahkan, berkorban, dan tanpa pamrih kepada orang-orang Kristen lainnya maupun kepada dunia. Dengan kasih seperti inilah dunia akan mengetahui bahwa orangorang Kristen sungguh-sungguh pengikutpengikut Kristus. ${ }^{42}$ Salah satu pekerjaan Roh Kudus dalam hidup orang percaya yaitu memberikan kekuatan. Dapat dikatakan bahwa Roh Kudus sebagai jaminan bagi orang percaya untuk mendapat kekuatan. Orang percaya memerlukan Roh Kudus sebagai kekuatan dalam menjalani kehidupan di dunia ini. Jadi, Roh Kudus adalah sumber kekuatan bagi setiap orang yang percaya kepada-Nya.

\section{Roh Kudus Jangan Didukakan} (Ef. 4:30)

Bagian ini dapat menunjukkan bahwa setiap sikap buruk terhadap sesama orang yang mengikut Kristus sama dengan sikap buruk terhadap Roh Kudus. Roh itulah yang memberikan persatuan dan perdamaian bagi jemaat yang adalah tubuh Kristus. ${ }^{43}$ O'brien menegaskan bahwa Roh Kudus didukakan ketika umat Allah terus melanjutkan dosa apa pun yang memisahkan dan menghancurkan kesatuan tubuh. ${ }^{44}$ Perintah ini mengingatkan tentang tanggung jawab moral yang teremban pada diri semua orang yang memiliki Roh. ${ }^{45}$ Matthew Henry menjelaskan tentang 'dan janganlah kamu mendukakan Roh Kudus Allah' dengan uraian sebagai berikut: Dengan melihat

\footnotetext{
${ }^{41}$ Morris, Teologi Perjanjian Baru, 114.

${ }^{42}$ James M. Boice, Dasar-Dasar Iman Kristen. (Surabaya: Momentum, 2011), 436-437.

${ }^{43}$ Bratcher dan Nida, Pedoman Penafsiran Alkitab

Surat Paulus Kepada Jemaat di Efesus, 120.

${ }^{44} \mathrm{O}$ 'brien. Surat Efesus, 423.

${ }^{45}$ Guthrie, Teologi Perjanjian Baru 2, 196.
}

apa yang dikatakan sebelumnya, dan apa yang dikatakan selanjutnya, kita bisa melihat apa itu yang mendukakan Roh Allah. Dalam ayat 25-29, tersirat bahwa semua kecemaran dan kenajisan, dusta, dan perkataan kotor yang memicu hawa nafsu kotor mendukakan Roh Allah. Dalam bagian selanjutnya tersirat bahwa nafsu bobrok seperti kepahitan, kegeraman, kemarahan, pertikaian, fitnah, dan kejahatan itu adalah mendukakan Roh yang baik ini. Kita tidak boleh melakukan apa yang bertentangan dengan sifatNya yang kudus dan kehendak-Nya. ${ }^{46}$

Surat Efesus menegaskan bahwa orang percaya jangan mendukakan Roh Kudus yang sudah mendiaminya. Pada saat orang percaya melakukan hal-hal yang bertentangan dengan Firman-Nya atau melakukan dosa, di saat itulah dia mendukakan Roh Kudus. Jadi, dosa yang dilakukan oleh setiap orang percaya membuat Roh Kudus didukakan. Mendukakan Roh Kudus, berarti tidak dipenuhi oleh Roh Kudus.

\section{Dipenuhi oleh Roh Kudus}

(Ef. 5:18)

Perintah untuk dipenuhi oleh Roh Kudus, dikontraskan dengan peringatan 'jangan mabuk oleh anggur'. Kemabukan memperlihatkan ketidakmampuan seseorang dalam menguasai dirinya sendiri. Natur dari kehidupan orang Kristen adalah kontras dengan natur dari pemabuk yang tidak terkontrol. Arti dari "dipenuhi" (Yun. plerousthe) adalah "penguasaan”. Roh Allah yang menyertai adalah pribadi yang harus secara terus-menerus mengontrol dan mendominasi kehidupan orang percaya. ${ }^{47}$ Dipenuhi dengan Roh berarti diisi penuh dengan Roh, maksudnya Roh itu mengisi orang Kristen dengan Roh itu sendiri, dan jemaat dianjurkan memohon agar Roh itu hidup dalam diri jemaat. Hendaknya jemaat dikuasai oleh Roh atau biarkanlah Roh yang mengatur jemaat. ${ }^{48}$ Matthew Henry menjelaskan bahwa

\footnotetext{
${ }^{46}$ Henry, Surat Galatia, Efesus, Filipi, Kolose, $1 \mathfrak{F} 2$ Tesalonika, Timotius, Titus, Filemon, 204.

${ }^{47}$ Enns, The Moody Handbook of Theology, 343.

${ }^{48}$ Robert G. Bratcher dan Eugene A. Nida. Pedoman Penafsiran Alkitab Surat Paulus Kepada Jemaat di Efesus. (Jakarta: Lembaga Alkitab Indonesia, 2013), 139.
} 
orang-orang yang mabuk oleh anggur tidak mungkin dipenuhi dengan Roh. Manusia berusaha dipenuhi oleh kasih karunia Roh, yang akan memenuhi jiwa mereka dengan sukacita, kekuatan, dan keberanian besar. Orang-orang yang dipenuhi dengan Roh akan dituntun ke dalam segala perbuatan saleh. ${ }^{49}$ Paulus menasihati untuk "terus-menerus dipenuhi oleh Roh,” Roh Kudus sebagai isi yang memenuhi orang percaya. "Hendaklah kamu penuh dengan Roh," berarti bahwa membiarkan Roh mengubah mereka semakin serupa dengan gambar Allah dan Kristus. Mereka yang dipenuhi oleh Roh Allah mampu memberikan pujian yang sepantasnya kepada Allah Tritunggal untuk semua yang telah Ia kerjakan. ${ }^{50}$ Walvoord dan Zuck mengemukakan bahwa orang percaya diperintahkan untuk terus-menerus dipenuhi oleh Roh Kudus,

"believers are commanded to be filled constantly with the Holy Spirit. Thus in this relationship, as a believer is yielded to the Lord and controlled by Him, he increasingly manifests the fruit of the Spirit (Gal. 5:22-23)."

Selanjutnya, Efesus 5:18 mengajarkan tiga faktor tentang konsep di penuhi oleh Roh Kudus, sebagai berikut: Pertama, hal itu adalah suatu perintah.Orang percaya diperintahkan untuk "terus-menerus dipenuhi oleh Roh Kudus" untuk kedewasaan dan pelayanan. Kedua, adalah bersyarat, pemenuhan oleh Roh Kudus adalah bersyarat. Ketaatan pada perintah lain di Kitab Suci adalah harus supaya dipenuhi oleh Roh Kudus. Ketiga, adalah berulang. Efesus 5:18 adalah dalam bentuk present imperatif, perintah untuk "terus-menerus dipenuhi." Hal ini mengindikasikan bahwa itu bukan merupakan pengalaman sekali saja, melainkan peristiwa yang berulang. ${ }^{52}$ Charles C. Ryrie berpendapat bahwa kepenuhan Roh Kudus dihubungkan dengan penyerahan. Ketika saya bersedia mengizinkan Roh Kudus untuk melakukan apa saja yang Dia

\footnotetext{
${ }^{49}$ Henry, Surat Galatia, Efesus, Filipi, Kolose, 1 E 2 Tesalonika, Timotius, Titus, Filemon, 222.

${ }^{50} \mathrm{O}$ 'brien, Surat Efesus, 478-481.

${ }^{51}$ Walvoord \& Zuck, The Bible Knowledge Commentary, 640.

${ }^{52}$ Enns, The Moody Handbook of Theology, 334.
}

kehendaki, maka terserah kepada-Nya untuk menggunakan diri saya apa saja yang Dia senangi. ${ }^{53}$ Baginya, ketika Roh Kudus menguasai kehidupan seseorang, maka buah-buah-Nya akan dihasilkan dalam hidup.

Berdasarkan uraian yang telah dikemukakan di atas, bahwa orang percaya diperintahkan untuk dipenuhi oleh Roh Kudus. Dipenuhi oleh Roh Kudus merupakan pengalaman yang harus terjadi secara terus menerus dalam hidup setiap orang percaya. Dipenuhi oleh Roh Kudus berarti dikontrol, dikendalikan, atau dikuasai oleh Roh Kudus. Jadi, Roh Kuduslah yang mengendalikan atau mengontrol hidup orang percaya.

\section{Roh Kudus Menuntun \\ Orang Percaya dalam Berdoa}

(Ef. 6:18)

Peter O'brien menjelaskan bagian ini dengan uraian sebagai berikut: Hidup yang bergantung pada Allah dalam doa sangatlah menentukan jika mereka ingin berhasil dalam peperangan melawan kuasa kegelapan. Orang percaya harus berdoa setiap waktu karena perjuangan mereka melawan kuasa kegelapan tidak pernah berakhir dan doa mereka harus "di dalam Roh", yaitu diinspirasikan dan dituntun oleh Roh Kudus, yang melalaui-Nya mereka memiliki jalan masuk kepada Bapa (2:18). Sebagai orang-orang yang telah turut dibangun menjadi tempat kediaman Allah di dalam Roh (2:22) dan penuh dengan Roh (5:18), mereka harus berdoa kepada Bapa, didorong dan dituntun oleh Roh. ${ }^{54}$ "When the enemy attacks-and on all occasions-Christians are to pray continually in the Spirit" (i.e., in the power and sphere of the Spirit; cf. Jude 20). ${ }^{55}$ Yang dimaksud Paulus dalam bagian ini adalah berdoa sebagai pekerjaan Roh. Untuk dapat menjalankan perjuangan mereka melawan kuasa-kuasa kegelapan di udara, anggota jemaat bukan saja membutuhkan pedang Roh (firman Allah), tetapi juga doa Roh - atau seperti yang dikatakan dalam ayat ini - doa di dalam Roh,

\footnotetext{
${ }^{53}$ Charles C. Ryrie, Teologi Dasar 2 (Yogyakarta: Yayasan ANDI, 1992), 164.

${ }^{54} \mathrm{O}$ 'brien, Surat Efesus, 583.

${ }^{55}$ Walvoord \& Zuck, The Bible Knowledge Commentary, 640.
} 
yang diucapkan setiap waktu, artinya terusmenerus. ${ }^{56}$ Selanjutnya, Ralph P. Martin mengemukakan bahwa Roh yang mengilhamkan orang Kristen untuk berdoa (bnd Rm. 8:26). ${ }^{57}$ Dalam segala doa dan permohonan ... di dalam Roh, dapat diartikan sebagai berdoa setiap saat dengan bimbingan Roh Kudus melalui semua atau segala doa dan permohonan atau berdoa setiap waktu di dalam Roh Kudus setiap kali berdoa dan memohon kepada Tuhan. Dalam arti lain bahwa Roh Allah memimpin atau Roh Kudus akan menolong untuk itu. ${ }^{58}$ Rumus doa dalam Alkitab ialah bahwa kita berdoa kepada Allah Bapa, melalui Allah Anak dan dengan kuasa Roh Kudus. ${ }^{59}$ Roh Kuduslah yang mengajar kita berdoa. Dan doa yang berkenan kepada Tuhan yaitu doa di dalam Roh Kudus, yaitu Roh Kudus sendiri yang berdoa di dalam kita. $^{60}$

Dalam tulisan Paulus kepada jemaat di Roma, ia berkata "Demikianlah juga Roh membantu kita dalam kelemahan kita; sebab kita tidak tahu, bagaimana sebenarnya harus berdoa; tetapi Roh Sendiri berdoa untuk kita kepada Allah dengan keluhan-keluhan yang tidak terucapkan” (Rm. 8:26). Keterbatasan tentu masih melekat dalam hidup orang percaya, karena itu Roh Kudus melakukan pekerjaan ini bagi orang percaya, Roh Kudus menuntun orang percaya berdoa. Hal ini merupakan jaminan komunikasi orang percaya dengan Allah dalam pelayanan atau pekerjaan Roh Kudus.

Jadi, pengajaran Roh Kudus yang disampaikan rasul Paulus kepada jemaat di Efesus sangat penting karena pertama, kehadiran Roh Kudus dalam diri orang percaya merupakan meterai yang menandakan bahwa orang percaya adalh milik Allah. Dengan kata lain bahwa Roh Kudus sebagai meterai. Kedua, Roh Kudus sebagai jaminan bahwa orang percaya akan

${ }^{56}$ J. L. Abineno, Tafsiran Alkitab Surat Efesus (Jakarta: BPK Gunung Mulia, 2003), 249.

${ }^{57}$ Martin, "Efesus" dalam Tafsiran Alkitab Masa Kini 3,607 .

${ }^{58}$ Bratcher dan Nida, Pedoman Penafsiran Alkitab Surat Paulus Kepada Jemaat di Efesus, 170-171.

${ }^{59}$ Warren W. Wiersbe, Kaya Di Dalam Kristus (Bandung: Kalam Hidup, 2001), 163.

${ }^{60} \mathrm{~J}$. Wesley Brill, Dasar Yang Teguh (Bandung: Kalam Hidup, t.t), 163. menerima berkat-berkat yang telah dijanjikanNya. Ketiga, Orang percaya adalah tempat kediaman Roh Allah atau Roh Kudus. Orang percaya menjadi Bait Allah atau tempat Allah tinggal melalui pekerjaan Roh Kudus. Keempat, Berdiamnya Roh Kudus dalam diri orang percaya menjadi jaminan bahwa Roh Kudus memberi kekuatan kepada orang percaya. Kelima, Tanggungjawab sebagai orang percaya yang sudah didiami Roh Kudus agar jangan mendukakan Roh Kudus dengan melakukan halhal yang bertentangan dengan sifat dan kehendak-Nya. Keenam, orang percaya diperintah untuk secara terus menerus dipenuhi oleh Roh Kudus, membiarkan Roh Kudusyang menguasai atau mengendalikan kehidupannya. Ketujuh, dalam menjalani perjuangan hidup di dunia ini, orang percaya harus berdoa setiap waktu, dan Roh Kudus menuntun orang percaya dalam berdoa. Dengan demikian, penekanan itu harus menjadi dasar dalam pengajaran mengenai Roh Kudus bagi gereja masa kini.

\section{Pembinaan Warga Jemaat Dewasa dan Pengajaran mengenai Roh Kudus}

Pemahaman warga jemaat mengenai Roh Kudus, salah satunya dipengaruhi oleh kurikulum pengajaran yang dilakukan dalam pembinaan warga jemaatnya. Bagaimana mungkin jemaat memiliki pemahaman mengenai Roh Kudus, kalau tidak diajarkan. Sidjabat dalam tulisannya mengemukakan bahwa pembinaan warga jemaat dewasa patut menuntun peserta untuk mempelajari pribadi dan karya Roh Kudus. ${ }^{61}$ Beberapa alasan pentingnya pengajaran mengenai Roh Kudus yang dikemukakan oleh Terok dalam bahan ajar Pneumatologi adalah: Pertama, Alkitab melaporkan tentang keberadaan dan karya Roh Kudus. Kedua, Roh Kudus sangat berhubungan dengan kehidupan orang percaya. Ketiga, Gereja dalam periode pelayanan Roh Kudus - Generasi ini (kita) hidup dalam pelayanan Roh Kudus. Keempat, Gereja memerlukan kesimpulan yang benar dan utuh tentang azas kepercayaan

${ }^{61}$ B. S. Sidjabat, Pendewasaan Manusia Dewasa (Bandung: Kalam Hidup, 2014), 57. 
berkenaan dengan Roh Kudus. Kelima, Pandangan terhadap Roh Kudus pada beberapa dekade akhir ini sangat menonjol, dan seringkali mempengaruhi orang percaya yang belum memahami pelayanan Roh Kudus. Keenam, Pengalaman secara mendalam terhadap pelayanan Roh Kudus kepada gereja (orang percaya). ${ }^{62}$ Pengajaran mengenai Roh Kudus harus menjadi perhatian gereja dan harus dilakukan dalam pembinaan warga jemaat dewasa supaya jemaat memahami dan mengetahui pelayanan atau karya Roh Kudus.

\section{Pembinaan Warga Jemaat Dewasa dan Pertumbuhan Rohani}

Pertumbuhan rohani seseorang erat kaitannya dengan pelaksanaan pembinaan warga jemaat yang dilakukan di gereja. Sidjabat dalam tulisannya mengemukakan bahwa pembinaan bagi orang dewasa itu perlu, tidak hanya bersifat mendesak (urgen), tetapi juga merupakan kebutuhan hakiki karena dinamika kehidupan orang dewasa itu beragam dan penuh tantangan. ${ }^{63}$ Pelaksanaan pembinaan bagi jemaat dewasa sebagaimana dalam Roma 12:1-2, bertujuan mengubah baik pikiran maupun kehidupan orang-orang yang terlibat. Begitu seseorang percaya, Allah menginginkan pertumbuhan agar Kristus dapat "menjadi nyata di dalam kamu” (Gal. 4:19). Tujuannya adalah untuk memimpin orang dewasa mencapai kedewasaan rohani. ${ }^{64}$ Kedewasaan atau maturitas tidak datang dengan sendirinya. Kedewasaan bertumbuh dalam diri kita melalui kegiatan belajar. ${ }^{65}$ Pertumbuhan rohani seseorang perlu proses untuk mencapai kedewasaan rohani dengan berbagai aspek yang merupakan proses belajar. "Ketika aku kanan-kanak, aku berkata seperti kanak-kanak, aku merasa seperti kanakkanak, aku berpikir seperti kanak-kanak. Sekarang sesudah aku menjadi dewasa, aku

${ }^{62}$ Sperry V. Terok, Bahan Ajar Pneumatologi (Pontianak: STK, 2019), 3.

${ }^{63}$ Sidjabat, Pendewasaan Manusia Dewasa, 21.

${ }^{64}$ James A. Davies, "Pelayanan Orang Dewasa" dalam Fondasi Pendidikan Abad 21 (Malang: Gandum Mas, 2017), 400 .

${ }^{65}$ Sidjabat, Pendewasaan Manusia Dewasa, iv. meninggalkan sifat kanak-kanak itu" (1 Kor. 13:11).

Andar Ismail dalam tulisannya mengemukakan ciri-ciri orang yang bertumbuh dalam kedewasaan. Pertama, mampu mengenali dan menerima diri sendiri. Kedua, mampu menerima keberadaan orang lain, bahkan bisa mengagumi keunggulan orang lain. Ketiga, mampu mengarahkan hidup kepada orang lain, perhatian, kepedulian dan cinta berjalan timbal balik atau dua arah. Keempat, mampu berpikir dan bertindak mandiri, tahu tugas dan tanggung jawab, serta mampu membedakan mana yang benar dan tidak benar. ${ }^{66}$ Pelaksanaan pembinaan warga jemaat dewasa sangat penting dan sangat berperan dalam pertumbuhan kedewasaan seseorang. Dengan kata lain bahwa kedewasaan rohani jemaat dewasa dipengaruhi oleh pelaksanaan pembinaan warga jemaat dewasa di gereja. Oleh karena itu, gereja harus melaksanakan pembinaan bagi warga jemaat dewasa supaya jemaat bertumbuh mencapai kedewasaan rohani. Davies mengemukakan, sebuah pelayanan untuk orang dewasa yang dirancang dengan baik dan koprehensif harus berada di garis depan perencanaan jangka panjang pelayanan di geraja. ${ }^{67}$ Gereja tidak boleh memandang rendah signifikansi pembinaan warga jemaat dewasa. Orang dewasa membutuhkan topangan dari gereja supaya mampu menunaikan tugas panggilannya, baik di dalam keluarga, gereja, tempat kerja, maupun di masyarakat secara luas. Orang dewasa membawa dampak perubahan moral dan spiritual. ${ }^{68}$

Pada akhirnya, orang dewasa melalui pelaksanaan pembinaan warga jemaat dewasa akan mewujudkan apa yang dikatakan oleh Tuhan Yesus "Kamu adalah garam dunia. ... Kamu adalah terang dunia. ... Demikianlah hendaknya terangmu bercahaya di depan orang, supaya mereka melihat perbuatanmu yang baik dan memuliakan Bapamu yang di sorga" (Mat. 5:13-16). Orang dewasa memerlukan pembinaan dalam menjalani kehidupan ini dalam segala

\footnotetext{
${ }^{66}$ Andar Ismail, Selamat Panjang Umur (Jakarta: BPK Gunung Mulia, 2015), 62-64.

${ }^{67}$ Davies, "Pelayanan Orang Dewasa" dalam Fondasi Pendidikan Abad 21, 415.

${ }^{68}$ Sidjabat. Pendewasaan Manusia Dewasa, 22.
} 
aspek untuk melakukankan tugas dan tanggung jawabnya sebagai gereja Tuhan, dan menjadi garam dan terang dunia. Orang dewasa memerlukan pembinaan supaya bertumbuh dalam kedewasaan, dan menjadi pribadi yang serupa dengan Kristus berdasarkan Firman-Nya dalam Roma 12:2 “... berubahlah oleh pembaharuan budimu, sehingga kamu dapat membedakan manakah kehendak Allah: apa yang baik, yang berkenan kepada Allah dan yang sempurna."

\section{Kedewasaan Rohani dan Kepenuhan Roh Kudus}

Pemenuhan oleh Roh Kudus dalam hidup orang percaya harus terjadi karena dua alasan: Pertama, esensial untuk kedewasaan orang percaya (1 Kor. 3:1-3). Kedua, esensial untuk pelayanan orang percaya (Kis. $4: 31 ; 9: 17,20) .{ }^{69}$ Alkitab menyatakan suatu perintah kepada orang percaya untuk dipenuhi oleh Roh Kudus yang ditulis dalam Efesus 5:18. Pertumbuhan rohani yang ada dalam tingkat kedewasaan itu yang menjadi syarat mutlak adalah kepenuhan Roh Kudus. ${ }^{70}$ Perintah kepada orang percaya untuk dipenuhi oleh Roh Kudus adalah bagian penting dalam perjalanan kehidupan rohani. Sidjabat dalam tulisannya mengemukakan bahwa kualitas komunikasi dan relasi kita dipengaruhi oleh mutu kerohanian kita. ${ }^{71}$ Dalam meningkatkan mutu kerohanian, orang percaya didorong untuk terus merindukan Roh Kudus agar supaya senantiasa memenuhi atau mengendalikannya. Sidjabat mengusulkan upaya untuk meningkatkan mutu kerohanian, yaitu: Tubuh dan penginderaan kita harus terus menerus dipersembahkan kepada Allah sebagai persembahan yang kudus dan berkenan kepadaNya. Pola pikir juga harus ikut mengalami pembaharuan. Sebaiknya kita berlatih cara memandang masalah atau kejadian dari segi positif agar lama kelamaan menjadi kebiasaan terpuji. Hati dan jiwa kita perlu menikmati relasi akrab dengan Tuhan Yesus, supaya Dia

\footnotetext{
${ }^{69}$ Enns, The Moody Handbook of Theology, 344.

${ }^{70}$ Terok, Bahan Ajar Pneumatologi, 29.

${ }^{71}$ Sidjabat, Mengajar Secara Profesional, 235.
}

mengerjakan pemunculan perangai yang baik, dan mengerjakan transformasi dalam hidup kita. Berdoa sebelum mengemukakan pendapat, khususnya mengambil keputusan penting. Dan memelihara sikap kehati-hatian dalam berkomunikasi dan membangun relasi, merupakan tanda spiritual yang baik. ${ }^{72}$

Perintah untuk dipenuhi oleh Roh Kudus berhubungan dengan relasi yang baik dengan Roh Kudus, maka kondisi yang menuasai relasi itu harus berkaitan dengan dipenuhi oleh Roh Kudus. ${ }^{73}$ Kepenuhan Roh Kudus yang dialami oleh orang percaya membawanya dalam suatu pengalaman yang indah, bertumbuh dalam kedewasaan rohani. Kepenuhan Roh Kudus dalam hidup orang percaya akan menghasilkan sifat hidup yang rohani sebagaimana yang ditulis oleh rasul Paulus kepada jemaat di Efesus (Ef. 5:15-21). Kepenuhan Roh Kudus dapat dialami oleh orang percaya yang sungguh-sungguh memiliki kehidupan rohani yang bertumbuh dalam kedewasaan. Roh Kudus mempengaruhi dan mengontrol orang percaya dalam melayani Allah dengan karakter hidup yang rohani. Orang percaya yang dipenuhi oleh Roh Kudus adalah orang yang memiliki kedewasaan rohani, atau sebaliknya orang yang memiliki kedewasaan rohani adalah orang yang dipenuhi oleh Roh Kudus. Kepenuhan Roh Kudus memberi pengaruh dalam kedewasaan rohani orang percaya, atau sebaliknya kedewasaan rohani seseorang dipengaruhi oleh kepenuhan Roh Kudus.

\section{KESIMPULAN}

Kajian Alkitab dalam surat Efesus mengenai Roh Kudus dapat menjadi landasan atau acuan bagi gereja untuk pelaksanaan kurikulum pengajaran tentang Roh Kudus bagi pembinaan warga jemaat dewasa. Surat Efesus mengajarkan bahwa Roh Kudus sebagai meterai, sewaktu kita percaya, kita dimeteraikan dengan Roh Kudus yang menandakan bahwa kita adalah milik Allah. Roh Kudus menjadi jaminan bahwa orang percaya akan menerima apa yang telah

\footnotetext{
${ }^{72}$ Ibid.

${ }^{73}$ Enns, The Moody Handbook of Theology, 345.
} 
dijanjikan-Nya. Orang percaya adalah tempat kediaman Roh Kudus. Roh Kudus mendiami orang percaya terjadi pada waktu seseorang percaya Yesus Kristus sebagai Tuhan dan Juruselamat pribadinya. Setiap orang percaya adalah bait Allah yang hidup, menjadi tempat kediaman Allah, di dalam Roh. Roh Kudus memberikan kekuatan kepada orang percaya. Orang percaya jangan mendukakan Roh Kudus, melainkan orang percaya diperintahkan untuk selalu dipenuhi, dikontrol, dikendalikan oleh Roh Kudus. Dan dalam menghadapi peperangan rohani, Roh Kudus menuntun orang percaya dalam berdoa, Roh Kudus berperan membantu orang percaya. Surat Efesus menekankan tentang pentingnya orang percaya agar dipimpin oleh Roh Kudus.

Sebagai masukan, penulis menyarankan kepada para pendidik khususnya dalan bidang pembinaan warga jemaat dewasa untuk diadakan penelitian yang sama dengan ini dalam konteks yang berbeda untuk dapat memperoleh data yang lebih akurat dan tajam, serta sebagai perbandingan untuk menemukan apakah gereja menyadari pentingnya pengajaran tentang Roh Kudus bagi pembinaan warga jemaat dewasa. Penelitian-penelitian yang dilakukan dapat memperkaya dan memotivasi serta menginspirasi bagi para pendidik untuk giat melaksanakan pembinaan warga jemaatnya.

Kemudian, penulis juga menyarankan untuk mengadakan penelitian terkait dengan dampak pelaksanaan pembinaan warga jemaat dewasa bagi kedewasaan rohani, sehingga dapat menemukan dan melihat perbandingan antara jemaat dewasa yang mengikuti kegiatan pembinaan warga jemaat dan yang tidak mengikuti kegiatan tersebut. Data yang diperoleh akan memperkaya dan mendorong gereja untuk aktif dalam pembinaan warga jemaat dewasa supaya jemaat mencapai kedewasaan rohani.

\section{KEPUSTAKAAN}

Abineno, J.L. Tafsiran Alkitab Surat Efesus. Jakarta: BPK Gunung Mulia, 2003.

Anthony, Michael J. Fondasi Pendidikan Abad 21. Malang: Gandum Mas, 2017.
Barclay, William. Pemahaman Alkitab Setiap Hari: Galatia dan Efesus. Jakarta: BPK Gunung Mulia, 1999.

Boice, James M. Dasar-Dasar Iman Kristen. Surabaya: Momentum, 2011.

Bratcher, Robert G. dan Nida, Eugene A. Pedoman Penafsiran Alkitab Surat Paulus Kepada Jemaat di Efesus. Jakarta: LAI dan YKBBI, 2013.

Brill, J. Wesley. Dasar Yang Teguh. Bandung: Kalam Hidup, T.t.

Davies, James A. "Pelayanan Orang Dewasa" dalam Fondasi Pendidikan Abad 21. Malang: Gandum Mas, 2017.

Enns, Paul. The Moody Handbook of Theology. Malang: Literatur SAAT, 2008.

Fee, G.D, dkk. "Roh Kudus" dalam Kamus Gambaran Alkitab. Surabaya: Momentum, 2011.

Geisler, Norman. "Siapakah Roh Kudus Itu?" dalam Pola Hidup Kristen. Malang: Gandum Mas, 2002.

Graham, Billy. Roh Kudus. Bandung: Lembaga Literatur Baptis, 2002.

Guthrie, Donald. Pengantar Perjanjian Baru Volume 2. Surabaya: Momentum, 2013.

Henry, Matthew. Surat Galatia, Efesus, Filipi, Kolose, 1 E 2 Tesalonika, 1 E 2 Timotius, Titus, Filemon. Surabaya: Momentum, 2015.

Ismail, Andar. Selamat Panjang Umur. Jakarta: BPK Gunung Mulia, 2015.

Martin, Ralph P. "Efesus" dalam Tafsiran Alkitab Masa Kini 3. Jakarta: Yayasan Komunikasi Bina Kasih, 2007.

Morris, Leon. Teologi Perjanjian Baru. Malang: Gandum Mas, 2006.

O'brien, Peter T. Surat Efesus. Surabaya: Momentum, 2013.

Ryrie, Charles C. Teologi Dasar 2. Yogyakarta: Yayasan ANDI. 1992.

Sadono, Sentot. Doktrin Baptis Diantara Pandangan Teologi Kristen. Semarang: STBI, 2011.

Selan, Ruth F. Pedoman Pembinaan Warga Jemaat. Bandung: Yayasan Kalam Hidup, 2000.

Sidjabat, B. S. Pendewasaan Manusia Dewasa. Bandung: Kalam Hidup, 2014. 
. Mengajar Secara Profesional. Bandung:

Kalam Hidup, 2017.

- Mendidik Warga Gereja Melalui Seri

Selamat. Jakarta: BPK Gunung Mulia, 2018.

. Pedoman Penulisan Tesis. Sekolah Tinggi Alkitab Tiranus, Bandung, 2015.

Stott, John R.W. Efesus. Jakarta: Yayasan Komunikasi Bina Kasih, 2003.

Tanya, Eli. Gereja dan Pendidikan Agama Kristen. Sekolah Tinggi Teologi Cipanas, 1999.

Terok, Sperry V. Bahan Ajar Pneumatologi. Sekolah Tinggi Teologi Kalimantan, Pontianak, 2019.

Walvoord, John F \& Zuck, Roy B. The Bible Knowledge Commentary. New York: Zondervan Bible Publishers, 1984.

Wiersbe, Marren W. Kaya Di Dalam Kristus. Bandung: Kalam Hidup, 2001.

Zaluchu, Sonny Eli. "Metode Penelitian di dalam Manuskrip Jurnal Ilmiah Keagamaan.” Jurnal Teologi Berita Hidup 3 No. 2 (2021): 249-266. 